Discussion Paper No. 744R

\title{
Pre-Play Communication in Two-Person Sealed-Bid Double Auctions
}

\author{
by \\ Steven Matthews \\ Northwestern University and The University of Pennsylvania \\ and \\ Andrew Postlewaite \\ The University of Pennsylvania \\ revised March 1988
}




\title{
Pre-Play Communication in Two-Person Sealed-Bid Double Auctions*
}

\author{
by \\ Steven Matthews \\ Northwestern University \\ Evanston, Illinois 60208 \\ and \\ Andrew Postlewaite \\ University of Pennsylvania \\ Philadelphia, Pennsylvania 19104
}

* This research was partially supported by grants from the National Science Foundation. We thank Bob Gibbons, George Mailath, and Steve Williams for useful conversations, as well as two referees and an associate editor for useful comments. We especially thank Françoise Forges, who alerted us to a critical error in a previous version. 

Running head: Communication in Double Auctions

Send proofs to: Professor Steven Matthews

Department of Economics

Northwestern University

Evanston, IL 60208 

B1 - Matthew's, Steven and Postlewaite, Andrew --

B2 - Pre-Play Communication in Two-Person Sealed-Bid Double Auctions

C2 - Allowing unmediated communication in a two-person double auction dramatically enlarges the set of equilibrium outcomes. It then consists of all allocation rules that are equilibrium outcomes of games in which all traders have the power at the end to veto proposed trades. All the allocation rules so characterized are equilibrium outcomes of a single game in which the traders exchange messages once before bidding in a double auction. These outcomes are all obtained by equilibria in which the traders truthfully tell each other their values. Adding a mediator achieves no further outcomes. Journal of Economic Literature Classification Numbers: 026, 021, 022.

B6 - J. Econ. Theory.

B7 -

B8 -

C4 -

B4 - Northwestern University, Evanston, Illinois, U.S.A.; University of Pennsylvania, Philadelphia, Pennsylvania, U.S.A.

Journal of Economic Literature Classification Numbers: 026, $021,022$. 


\section{Introduction}

The currently predominant approach to the study of bargaining and trading institutions is rooted in Nash [20] and exposited in Wilson [27, 28]. Its basic tenet is that institutions can be evaluated by studying the noncooperative games that reflect their relevant features. It is often acknowledged that this approach can fail if the game does not represent all the real-world actions allowed to traders, and also if the game has multiple equilibria. Yet, we maintain that in environments with incomplete information, these two problems are more severe than is generally recognized. The real-world actions that we are concerned with, and which have almost never been formally considered, are pre-trade communications among the traders. It is our claim that following the Nash program to the point of strategically modelling communication can greatly exacerbate the multiplicity problem.

To establish this claim, we consider the sealed-bid double auctions studied initially by Chatterjee and Samuelson [3]. The environment is standard: a risk neutral seller initially owns an indivisible item that a risk neutral buyer may wish to purchase, and their evaluations of the item are privately known. Given a number $k \in[0,1]$, the rules of a $\mathrm{k}$-double auction require that both traders submit bids, that trade occurs if the bid of the buyer exceeds that of the seller, and that the price when trade occurs is a weighted average of the bids, with the weight on the buyer's bid being $\mathrm{k}$. Double auctions have served as noncooperative models of bargaining when commitment is possible $[3,17,19]$, and of markets when generalized to many buyers and sellers $[26,27]$. They have also been the subject of considerable experimental scrutiny $[21,24]$.

Attention is usually restricted to a particularly tractable equilibrium of a double auction, e.g. the linear equilibria found by Chatterjee and Samuelson in the uniform case. Even without considering pre-play communication, selecting this equilibrium may be questionable in view of the significant multiplicities of equilibria uncovered by Leininger, Linhart, and Radner [13] and Satterthwaite and Williams [23]. One's confidence in this 
selection should be further eroded by our main result: pre-play communication dramatically enlarges the set of equilibrium outcomes of a double auction.

A corollary of our results is that allowing for communication renders the set of equilibrium outcomes invariant with respect to the double auction's parameter $\mathrm{k}$. Thus, the real-world outcome of a k-double auction may not only be far off what is predicted from a model that neglects communication possibilities, but it may not even depend upon what is supposedly a design parameter of the auction.

The largest caveat to our results, in our opinion, is that they rely on simultaneous message exchange, i.e., on both players talking at the same time. Most (but not all!) realworld conversations are sequential, with only one person talking at a time. (This issue is discussed further in the concluding section.)

We have mentioned here only a sampling of the results. Broadly speaking, we obtain a complete characterization of the equilibrium outcomes allowed by mediated and unmediated communication in double auctions - the concluding remarks in Section 5 give a thorough summary. In Section 2 the model is presented. In Section 3, as an introductory special case, the monopoly and monopsony allocations are shown to be equilibrium outcomes of any two-person double auction in which the traders can communicate. Section 4 contains statements and discussions of the theorems, and the Appendix contains their proofs. Section 5 contains remarks on the results, possible extensions, and the literature.

\section{The Model}

The seller's value (type) for the item is $v_{1}$ and the buyer's is $v_{2}$. Each trader knows only his own value. It is common knowledge that trader $j \neq i$ believes that $v_{i}$ is the realization of a random variable $\widetilde{v}_{i}$ that has a distribution $F_{i}$ on an interval $T_{i}=\left[a_{i}, b_{i}\right]$. Trade is assumed to be possibly beneficial: $a_{1}<b_{2}$. No further assumptions are made about the distributions $F_{i}$ - they need not be continuous, for example.

An allocation is a pair of numbers, a probability of trade and an expected payment of money from the buyer to the seller. If the item is traded with probability $\mathrm{p}$ and the expected payment is $\mathrm{x}$, the buyer's expected utility is $\mathrm{v}_{2} \mathrm{p}-\mathrm{x}$ and the seller's expected utility is $\mathrm{x}-\mathrm{v}_{1} \mathrm{p}$. 
What has been defined so far is a particular Bayesian collective choice environment (a slight paraphrase of Myerson's [18] term). An allocation rule for this environment is a mapping $(p, x)$ that determines a trade probability $p\left(v_{1}, v_{2}\right) \in[0,1]$ and an expected payment $\mathrm{x}\left(\mathrm{v}_{1}, \mathrm{v}_{2}\right) \in \mathfrak{R}$ for each pair $\left(\mathrm{v}_{1}, \mathrm{v}_{2}\right)$ of trader types.

Given an allocation rule $(\mathrm{p}, \mathrm{x})$, define functions $\mathrm{U}_{\mathrm{i}}: \mathrm{T}_{\mathrm{i}}{ }^{2} \rightarrow \mathfrak{X}$ by

$$
\mathrm{U}_{1}\left(\mathrm{r}_{1}, \mathrm{v}_{1}\right) \equiv E\left[\mathrm{x}\left(\mathrm{r}_{1}, \tilde{\mathrm{v}}_{2}\right)-\mathrm{v}_{1} \mathrm{p}\left(\mathrm{r}_{1}, \tilde{\mathrm{v}}_{2}\right)\right] \quad \text { and } \quad \mathrm{U}_{2}\left(\mathrm{r}_{2}, \mathrm{v}_{2}\right) \equiv E\left[\mathrm{v}_{2} \mathrm{p}\left(\tilde{\mathrm{v}}_{1}, \mathrm{r}_{2}\right)-\mathrm{x}\left(\tilde{\mathrm{v}}_{1}, \mathrm{r}_{2}\right]\right.
$$

The allocation rule is incentive compatible if

$$
\mathrm{U}_{\mathrm{i}}\left(\mathrm{v}_{\mathrm{i}}, \mathrm{v}_{\mathrm{i}}\right) \geq \mathrm{U}_{\mathrm{i}}\left(\mathrm{r}_{\mathrm{i}}, \mathrm{v}_{\mathrm{i}}\right) \text { for all } \mathrm{r}_{\mathrm{i}}, \mathrm{v}_{\mathrm{i}} \in \mathrm{T}_{\mathrm{i}} \text { and } \mathrm{i}=1,2 \text {. }
$$

An allocation rule satisfies IC if and only if it is an equilibrium outcome of a Bayesian game defined by adding a "mechanism" to the environment, where a mechanism (for this environment) is a set of actions for each player and a mapping that takes pairs of actions into allocations. (An equilibrium outcome of a Bayesian game, in this paper, is the allocation rule induced by an equilibrium.) Given a ( $\mathrm{p}, \mathrm{x})$ satisfying $\mathrm{IC}$, one game in which it is an equilibrium outcome is formed from the revelation mechanism based on $(\mathrm{p}, \mathrm{x})$. In this mechanism, each player $i$ reports that his type is $r_{i}$, whereupon the mechanism specifies that trade occurs with probability $p\left(r_{1}, r_{2}\right)$ and that the payment is $x\left(r_{1}, r_{2}\right)$. The incentive compatibility of $(\mathrm{p}, \mathrm{x})$ insures that truth-telling is an equilibrium of the game defined by adding this mechanism to the Bayesian collective choice environment. (For more on this "revelation principle" argument, see the Myerson [18] survey.)

Often, a mechanism designer is constrained to allow each player to choose whether to participate. In this case, the mechanism must give each type of each player an expected utility no less than what that type of player gets by not participating. In our environment this means that the resulting allocation rule must be interim individually rational in the following sense:

(INTIR) $\quad U_{i}\left(v_{i}, v_{i}\right) \geq 0$ for all $v_{i} \in T_{i}$ and $i=1,2$. 
The feasible set of allocation rules, the characterization of which is the main accomplishment of Myerson and Satterthwaite [19], is then

$$
A \equiv\{(p, x) \mid I C \text { and INTIR are satisfied }\}
$$

A $k$-double auction, where $\mathrm{k} \in[0,1]$, is a particular mechanism that resembles various real-world trading and bargaining institutions. The seller and buyer in this mechanism simultaneously submit bids, $\beta_{1}$ and $\beta_{2}$. Trade occurs if and only if the higher bid is the buyer's: $\beta_{2} \geq \beta_{1}$. A nonzero payment is made by the buyer to the seller if and only if trade occurs, in which case the payment is $k \beta_{2}+(1-k) \beta_{1}$. We denote by $D(k)$ the Bayesian game defined by adding this mechanism to our Bayesian environment. This is the game studied, for example, in $[3,13,23]$.

The games studied in this paper are communication-bidding games. Such a game is defined by adding a "communication mechanism" to a k-double auction game $\mathrm{D}(\mathrm{k})$, where a communication mechanism (for a double auction) is a device through which the buyer and seller can communicate before they submit their bids. A communication mechanism receives messages from the traders and transmits messages to the traders; in general, there may be several rounds of message exchange, and neither trader may see the messages of the other. We denote by $\mu(\mathrm{k})$ a Bayesian game defined by adding a communication mechanism to to a $\mathrm{k}$-double auction game $\mathrm{D}(\mathrm{k})$.

A particular kind of communication mechanism is a revelation-suggestion mechanism, which can be described as a mechanical "mediator" to whom the traders confidentially reveal their types and who, subsequently, confidentially suggests to each trader a particular bid to make. The "general revelation principle" (Myerson $[16,18]$, Forges [7]) states that there is no loss of generality in restricting attention to revelationsuggestion mechanisms in which one equilibrium of the resulting game consists of the traders honestly revealing their types and obediently submitting the suggested bids. More precisely, this principle states that if $(\mathrm{p}, \mathrm{x})$ is an equilibrium outcome of a communicationbidding game $\mu(\mathrm{k})$, then another communication-bidding game $\mu^{\prime}(\mathrm{k})$ exists in which the 
communication mechanism is a revelation-suggestion mechanism, honest and obedient behavior constitutes an equilibrium, and $(p, x)$ is the corresponding equilibrium outcome.

We are especially interested in another kind of communication-bidding game, an unmediated communication-bidding game. In such a game the communication is meant to be face-to-face, taking place without a mediator. The formal description in terms of a communication mechanism requires the mechanism merely to relay, accurately, each player's messages to the other. Explicit reference to a mechanism is therefore unnecessary; it is simpler to assume that each trader's messages are directly received by the other player. Accordingly, we consider unmediated communication-bidding games as having two stages, a message stage in which the players exchange messages, followed by a bidding stage in which they play a k-double auction. The message stages in the particular games we shall study consist of a single round of simultaneous message exchange.

An unmediated communication-bidding game of this sort was first studied by Farrell and Gibbons [6]; we defer until later a discussion of their results. Similar economic games which differ in that the second stage is other than a double auction are studied, for example, in $[4,8,14]$. Issues that arise in general with unmediated communication are considered by Farrell [5], Barany [2], and Forges [9]; the latter two papers are discussed below.

Thus far we have used the term "equilibrium of a Bayesian game" with the usual, unrefined definition in mind (see, e.g., the Myerson [18] survey). But it is convenient to refine the definition in a small way. Henceforth, an equilibrium of a communicationbidding game is an equilibrium in which, in the bidding stage, the seller never bids less than his value and the buyer never bids more than his value. Throwing out such strategies can be justified by the observation that they are dominated. For example, a strategy for the seller that prescribes that he bid below his value when his value is $v_{1}$ is dominated by a strategy that differs only by having this type of seller bid $v_{1}$. Thus, the seller would submit a bid less than his value in an equilibrium only if that bid and every higher bid almost surely results in no trade. Altering an equilibrium strategy in the way just described will result in another equilibrium that gives all types of both traders the same (interim) expected 
utilities. This refinement, therefore, does not eliminate any equilibrium that differs in an economically interesting way from an equilibrium that is not eliminated.

Before beginning our analysis of communication-bidding games, we first observe that communication can only expand a double auction's set of equilibrium outcomes. That is, an equilibrium outcome $(p, x)$ of a double auction game $D(k)$ is also an equilibrium outcome of any communication-bidding game $\mu(\mathrm{k})$ based on $\mathrm{D}(\mathrm{k})$. One equilibrium of $\mu(\mathrm{k})$ that has $(\mathrm{p}, \mathrm{x})$ as an outcome is the following: the traders send messages to the mechanism according to probability distributions that are independent of their types, and they submit bids according to the given equilibrium of $D(k)$, regardless of any of the messages. (Such babbling equilibria are discussed, e.g., in $[5,14]$.)

If the equilibrium outcomes of $D(k)$ were to be the only equilibrium outcomes of the unmediated communication-bidding games $\mu(\mathrm{k})$, an economist could justifiably study double auctions without taking account of communication. Unfortunately, this is not the case.

\section{The Buyer's and Seller's Best Allocation Rules}

As an introduction to the general results, we now indicate how unmediated communication in any $\mathrm{k}$-double auction can achieve three particularly interesting allocation rules: the buyer's best allocation rule, the seller's best allocation rule, and a convex combination of the two.

The argument relies on a particular class of double auction equilibria. Define, for any $\mathrm{z} \in \Re$ and $\left(\mathrm{v}_{1}, \mathrm{v}_{2}\right) \in \mathrm{T}_{1} \times \mathrm{T}_{2}$, the following bidding strategies:

$$
\beta_{1}^{z}\left(v_{1}\right)=\left\{\begin{array}{l}
z \text { if } v_{1} \leq z \\
b_{2} \text { otherwise }
\end{array} \quad \beta_{2}^{z}\left(v_{2}\right)=\left\{\begin{array}{l}
z \text { if } v_{2} \geq z \\
a_{1} \text { otherwise }
\end{array}\right.\right.
$$

Trade occurs according to these strategies only at the price $\mathrm{z}$, and precisely when both traders can profit by trading at this price. It is easy to show that these strategies constitute a perfect Bayesian equilibrium of $D(k)$ for any $k \in[0,1]$, regardless of the beliefs $F_{1}$ and $F_{2}$. 
Discussed originally by Leininger, Linhart and Radner [13], we refer to such an equilibrium as a single-price equilibrium.

Consider first the buyer's best allocation rule in A, the set of IC and INTIR allocation rules. The most preferred such allocation rule of a type $v_{2}$ buyer - given his beliefs $F_{1}$ about the seller's value - would be achieved if he were to quote a take-it-or-leave-it price $z$ that maximizes $\left(\mathrm{v}_{2}-\mathrm{z}\right) \mathrm{F}_{1}(\mathrm{z})$, and the seller were to accept this price precisely when it exceeded his value (see $[17,22,25]$ ). That is, the buyer's best allocation rule in $A$ is

$$
p^{2}\left(v_{1}, v_{2}\right)=\left\{\begin{array}{ll}
1 & \text { if } v_{1} \leq z^{2}\left(v_{2}\right) \\
0 & \text { otherwise }
\end{array} \quad x^{2}\left(v_{1}, v_{2}\right)=\left\{\begin{array}{c}
z^{2}\left(v_{2}\right) \text { if } v_{1} \leq z^{2}\left(v_{2}\right) \\
0 \text { otherwise }
\end{array}\right.\right.
$$

where, for all $\mathrm{v}_{2} \in \mathrm{T}_{2}, \mathrm{z}^{2}\left(\mathrm{v}_{2}\right)$ is the type $\mathrm{v}_{2}$ buyer's optimal price:

$$
\mathrm{z}^{2}\left(\mathrm{v}_{2}\right) \in \underset{\mathrm{z}}{\operatorname{argmax}}\left(\mathrm{v}_{2}-\mathrm{z}\right) \mathrm{F}_{1}(\mathrm{z}) .
$$

This best allocation rule for the buyer is an equilibrium outcome of $D(1)$, the $k=1$ double auction: as the price in this auction is determined entirely by the buyer's bid, the seller's dominant strategy is to bid his true value, and the buyer's best response is to bid his optimal price. However, if $k<1$, then $\left(p^{2}, x^{2}\right)$ is not an equilibrium outcome of $D(k)$. [Proof: if $k<1$, a type $\mathrm{v}_{1}$ seller who trades with positive probability should, for some $\varepsilon>0$, never submit a bid in the interval $\left[\mathrm{v}_{1}, \mathrm{v}_{1}+\varepsilon\right)$. For, increasing such a bid to $\mathrm{v}_{1}+\varepsilon$ results in a second order loss (a first order loss in probability of trade times a first order profit then foregone), but a first order gain (a first order gain in profit when trade occurs times a positive probability of trade). Thus, this seller never trades with a type $v_{2}$ buyer for whom $z^{2}\left(v_{2}\right) \in\left[v_{1}, v_{1}+\varepsilon\right)$, as $\left(p^{2}, x^{2}\right)$ would require. $]$ Similarly, if we let $\left(p^{1}, x^{1}\right)$ denote the seller's best allocation rule in $\mathrm{A}$, then $\left(\mathrm{p}^{1}, \mathrm{x}^{1}\right)$ is an equilibrium outcome of the double auction $D(k)$ if and only if $k=0$.

We now show that unmediated communication in any k-double auction can achieve $\left(\mathrm{p}^{2}, \mathrm{x}^{2}\right)$, even if $\mathrm{k}=0$. The simplest unmediated communication-bidding game which does this allows the buyer to suggest a price to the seller before they submit their bids. Consider 
the strategies for this game according to which the buyer suggests the optimal price for his type, $z=z^{2}\left(v_{2}\right)$, and he and the seller then play the single-price bidding strategies $\left(\beta_{1}^{z}, \beta_{2}^{z}\right)$. The resulting outcome is obviously $\left(\mathrm{p}^{2}, \mathrm{x}^{2}\right)$. Since this allocation rule is best for the buyer, his strategy is a best reply to that of the seller. And since $\left(\beta_{1}^{z}, \beta_{2}^{z}\right)$ is an equilibrium of $D(k)$ regardless of the value of $\mathrm{z}$ and regardless of how the beliefs have been updated, this strategy pair is an equilibrium.

In this equilibrium, the price suggested by the buyer is "cheap talk" as opposed to a true take-it-or-leave-it offer, since he cannot commit himself to later bidding the price he had suggested. Nevertheless, his suggested price has the effect of a take-it-or-leave-it offer by its selection of a single-price equilibrium for the double auction.

Communication can also achieve convex combinations of the buyer's and the seller's best allocation rules. Take, for example, $(\overline{\mathrm{p}}, \overline{\mathrm{x}}) \equiv(1 / 2)\left(\mathrm{p}^{1}, \mathrm{x}^{1}\right)+(1 / 2)\left(\mathrm{p}^{2}, \mathrm{x}^{2}\right)$. It can be easily obtained with mediated communication. Note first that it is a correlated equilibrium outcome of any communication-bidding game in which both traders can suggest prices before they bid. The correlated equilibrium consists of each trader i first suggesting his own optimal price, $z^{i}\left(v_{i}\right)$. Then a 50-50 randomization device is operated to select one of their suggested prices to be the price that defines a single-price double auction equilibrium that they will play. By our definitions, this randomization device is a communication mechanism (it transmits but does not receive messages). Thus, its addition to the game results in a mediated communication-bidding game $\mu(\mathrm{k})$ that has $(\overline{\mathrm{p}}, \overline{\mathrm{x}})$ as an equilibrium outcome.

The allocation rule $(\overline{\mathrm{p}}, \overline{\mathrm{x}})$ can also be obtained from an unmediated communicationbidding game. In this game, each trader i suggests a price and announces a number, $y_{i} \in\{0,1\}$. An equilibrium consists of each trader i suggesting his own optimal price, $z^{i}\left(v_{i}\right)$, announcing $y_{i}=0$ with probability $1 / 2$ and $y_{i}=1$ with probability $1 / 2$, and then bidding according to the single-price strategy $\beta_{\mathrm{i}}^{\mathrm{z}}$, where $\mathrm{z}=\mathrm{z}^{1}\left(\mathrm{v}_{1}\right)$ if $\mathrm{y}_{1}=\mathrm{y}_{2}$ and $\mathrm{z}=\mathrm{z}^{2}\left(\mathrm{v}_{2}\right)$ if $y_{1} \neq y_{2}$. According to these strategies, there is a one-half chance that each trader's optimal price will be the price in the single-price equilibrium played in the bidding stage. Thus, the outcome is $(\overline{\mathrm{p}}, \overline{\mathrm{x}})$. These strategies do form an equilibrium: neither player can unilaterally 
alter the probability distribution over single-price equilibria to be played in the bidding stage, and neither player will want to deviate from suggesting his own optimal price.

[This equilibrium produces the correlation as a result of the players using independent mixed strategies instead of an exogenous randomization device. Such "jointly controlled lotteries," which result in mixtures of Nash equilibria, were first discussed by Aumann, Maschler and Stearns [1]. (See also [5, 11].)]

\section{The Theorems}

Before continuing our study of unmediated communication, it is useful to consider general communication-bidding games. In particular, it is useful to derive two conditions necessarily satisfied by the equilibrium outcomes of any communication-bidding game.

Given an allocation rule $(\mathrm{p}, \mathrm{x})$, define functions $\mathrm{U}_{\mathrm{i}}^{*}: \mathrm{T}_{\mathrm{i}}{ }^{2} \rightarrow \Re$ by

$$
\begin{aligned}
& \mathrm{U}_{1}^{*}\left(\mathrm{r}_{1}, \mathrm{v}_{1}\right) \equiv \mathrm{E}\left[\max \left\{0, \mathrm{x}\left(\mathrm{r}_{1}, \tilde{\mathrm{v}}_{2}\right)-\mathrm{v}_{1} \mathrm{p}\left(\mathrm{r}_{1}, \tilde{\mathrm{v}}_{2}\right)\right\}\right], \text { and } \\
& \mathrm{U}_{2}^{*}\left(\mathrm{r}_{2}, \mathrm{v}_{2}\right) \equiv \mathrm{E}\left[\max \left\{0, \mathrm{v}_{2} \mathrm{p}\left(\tilde{\mathrm{v}}_{1}, \mathrm{r}_{2}\right)-\mathrm{x}\left(\tilde{\mathrm{v}}_{1}, \mathrm{r}_{2}\right)\right\}\right] .
\end{aligned}
$$

The two necessary conditions are defined in terms of these functions. Say that $(\mathrm{p}, \mathrm{x})$ satisfies incentive compatibility starred if

$$
\mathrm{U}_{\mathrm{i}}^{*}\left(\mathrm{v}_{\mathrm{i}}, \mathrm{v}_{\mathrm{i}}\right) \geq \mathrm{U}_{\mathrm{i}}^{*}\left(\mathrm{r}_{\mathrm{i}}, \mathrm{v}_{\mathrm{i}}\right) \text { for all } \mathrm{r}_{\mathrm{i}}, \mathrm{v}_{\mathrm{i}} \in \mathrm{T}_{\mathrm{i}} \text { and } \mathrm{i}=1,2 \text {, }
$$

and that it is ex post individually rational if

(EXPIR) $\quad x\left(v_{1}, v_{2}\right)-v_{1} p\left(v_{1}, v_{2}\right) \geq 0 \quad$ and $\quad v_{2} p\left(v_{1}, v_{2}\right)-x\left(v_{1}, v_{2}\right) \geq 0 \quad$ for all $\left(v_{1}, v_{2}\right)$. Any allocation rule that satisfies both $\mathrm{IC}^{*}$ and EXPIR satisfies IC and INTIR. As the converse is false (see Example 1 below), the set defined by

$$
A^{*} \equiv\left\{(p, x) \mid I C^{*} \text { and EXPIR are satisfied }\right\}
$$

is a subset of the feasible set $\mathrm{A}$ defined in (2). (For nondegenerate type distributions, $\mathrm{A}^{*}$ is a proper subset of A; see Example 1 below.) 
Conditions IC $^{*}$ and EXPIR have a natural interpretation. Recall the Bayesian collective choice environment defined in Section 2. Suppose that a mechanism designer is constrained to choose a mechanism that first publicly proposes an allocation $(\hat{p}, \hat{x}) \in[0,1] \times \Re$ in response to actions taken by the traders, and then allows each trader to choose, as a final action, whether or not to reject $(\hat{p}, \hat{x})$. If either player rejects, no trade occurs and no payment is made. An allocation rule is an equilibrium outcome achieved by such a mechanism if and only if the allocation rule satisfies IC ${ }^{*}$ and EXPIR. Thus, $\mathrm{A}^{*}$ is the feasible set of allocations when the traders have final rights of refusal.

Our first theorem indicates that $A^{*}$ is also the relevant set of allocation rules when considering communication-bidding games. It states that only allocation rules in $\mathrm{A}^{*}$ are equilibrium outcomes of communication-bidding games:

Theorem 1: $A^{*}$ contains all equilibrium outcomes of any communication-bidding game $\mu(k)$, for any $k \in[0,1]$.

Notes on the Proof (full proofs are in the Appendix): Much of the proof is similar to the argument mentioned above for why any mechanism in our environment that allows the traders final rights of refusal can yield only allocation rules satisfying $I^{*}$ and EXPIR. This is because a double auction, when combined with any communication mechanism, is a mechanism that in essence gives the traders final rights of refusal. The seller, for example, can insure that he never receives a negative profit, regardless of what messages he has sent or received, by simply refusing to never bid below his value. Thus, if the mechanism is a revelation-suggestion mechanism for which honest and obedient behavior is an equilibrium, a type $\mathrm{v}_{1}$ seller receives an expected utility no less than $U_{1}^{*}\left(\mathrm{r}_{1}, \mathrm{v}_{1}\right)$ by reporting that he is of type $r_{1}$ and then bidding either $\mathrm{v}_{1}$ or the bid suggested by the mechanism, whichever is larger. His equilibrium expected utility therefore exceeds $U_{1}^{*}\left(r_{1}, v_{1}\right)$, which proves IC* 
We now return to unmediated communication. In general games, fewer outcomes can be achieved with unmediated than with mediated communication $[2,7,9,18]$. For example, when all messages are transmitted through a mediator, the information one player receives about another's type need not be independent of his own type. Or, as another example, some correlated equilibria of some two-person games can only be implemented by a mediator (see [2]). However, when the game to be played is a double auction, our next theorem indicates that unmediated communication achieves any outcome that mediated communication does.

We consider a specific unmediated communication-bidding game, although it will be clear that many others have the same equilibrium outcomes. The one we consider has a single round of simultaneous message exchange. That there is only one round of message exchange is not important. But it is important that the messages are sent simultaneously rather than sequentially. These issues are discussed later, in Remark 5 in Section 5. It is also important that the traders have rich enough message sets; we assume they are given, for the seller and buyer respectively, by

$$
\mathrm{M}_{1} \equiv \mathrm{T}_{1} \times[0,1] \quad \text { and } \quad \mathrm{M}_{2} \equiv \mathrm{T}_{2} \times[0,1]
$$

The unmediated communication-bidding game in which a messages from these sets are exchanged simultaneously before bids are submitted in a k-double auction is denoted $\Gamma(\mathrm{k})$.

Theorem 2 concerns the "full communication equilibria" of $\Gamma(\mathrm{k})$. A full communication equilibrium is an equilibrium in which no two types of a player ever send the same message. Each trader can then infer the other's type from the message he sends. (The equilibria discussed in Section 3 were of this form.)

Theorem 2: $\mathrm{A}^{*}$ is the set of full communication equilibrium outcomes of the unmediated communication-bidding game $\Gamma(\mathrm{k})$, for any $k \in[0,1]$.

Notes on the Proof: The proof is based on the ideas introduced in Section 3, relying on single-price equilibria (3) and jointly controlled lotteries. To obtain a given allocation in 
$\mathrm{A}^{*}$, an equilibrium is constructed in which the players honestly tell each other their types, and afterwards they play the single-price equilibrium of the double auction that gives them the allocation specified by the allocation rule. They each also announce a number, drawn independently from a uniform distribution on $[0,1]$. These two random numbers are used to realize a joint lottery if the putative allocation has a nondegenerate probability of trade. The joint lottery determines whether they will play a single-price equilibrium in which they trade or one in which they do not .

Probably the most important implication of Theorems 1 and 2 is that allowing unmediated communication in a double auction enlarges the set of equilibrium outcomes as much as possible, so that it coincides with the entire set of outcomes that could have been obtained by instead adding various types of mediators to the auction. (Other implications are discussed in the concluding section.) In our opinion, this is an unfortunate implication for mechanism designers. Consider, for example, the problem of a designer who must chose the parameter $\mathrm{k}$ of a double auction. The usual approach to such a problem is to choose $\mathrm{k}$ on the basis of the welfare properties of the equilibrium outcomes of the double auction $\mathrm{D}(\mathrm{k})$. This approach requires a good equilibrium selection argument, as double auctions have large sets of equilibria [13, 23]. Our results imply that if, as is likely, the traders can converse with each other before they submit bids, the required selection argument must be much stronger. For then, the set of equilibrium outcomes does not even depend on the parameter $k$. Furthermore, given that the set $A^{*}$ is vast, the outcomes of a double auction in the real-world (with real-world communication possibilities) may be far different from any equilibrium outcome of any formal double auction game.

It remains to show that $\mathrm{A}^{*}$ actually is vast. The following example shows that it is not the full set A of allocation rules satisfying IC and INTIR.

Example 1: The seller has value $v_{1}=0$ or $v_{1}=2$, each with probability one-half. The buyer has value $\mathrm{v}_{2}=1$ or $\mathrm{v}_{2}=4$, each with probability one-half. The allocation rule $(\mathrm{p}, \mathrm{x})$ is given by 

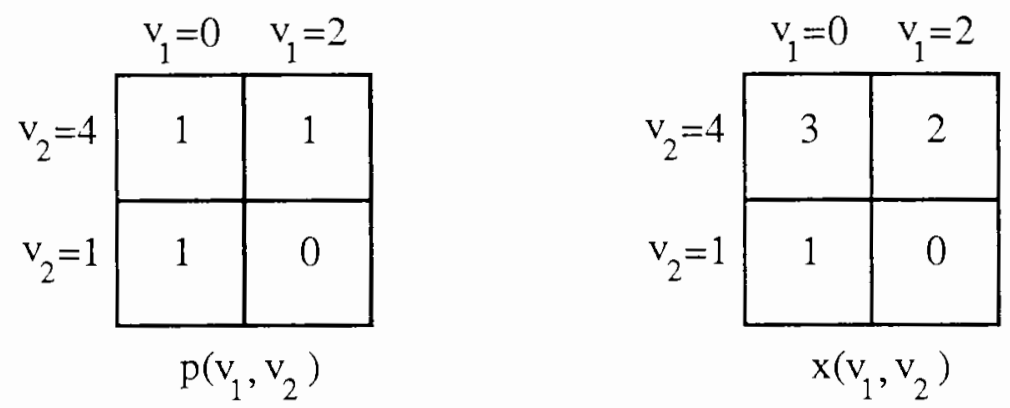

[To make this allocation rule conform to our definitions, we must extend it to a domain that is a cross-product of intervals. Any allocation rule defined and incentive compatible at a finite number of points $\left(\mathrm{v}_{1}, \mathrm{v}_{2}\right)$ can be extended to an incentive compatible rule defined on a cross-product of intervals. To do this here, define $(p, x)$ on $[0,2] \times[1,4]$ by $(p, x)=(1,3)$ if $\mathrm{v}_{1}<2$ and $\mathrm{v}_{2}=4,(\mathrm{p}, \mathrm{x})=(1,2)$ if $\mathrm{v}_{1}=2$ and $\mathrm{v}_{2}=4,(\mathrm{p}, \mathrm{x})=(1,1)$ if $\mathrm{v}_{1}<2$ and $\mathrm{v}_{2}<4$, and $(p, x)=(0,0)$ if $v_{1}=2$ and $v_{2}<4$.] This allocation rule is easily verified to satisfy EXPIR and IC, so that it is in A. It is not in $\mathrm{A}^{*}$ because it does not satisfy IC*: if the seller is able to enforce unilaterally the no-trade allocation once he has seen the putative allocation, then, when his value is $v_{1}=2$, he will report that his value is $r_{1}=0$ and, subsequently, refuse to trade whenever the putative allocation turns out to be $(\mathrm{p}, \mathrm{x})=(1,1)$ (the price, 1 , does not cover his cost, 2). This strategy gives him expected utility $(.5)(3-2)+(.5)(0)=.5$, whereas reporting his type truthfully gives him only $(.5)(2-2)+(.5)(0)=0$.

We now show that $\mathrm{A}^{*}$ contains a large set of allocation rules defined by two conditions that are economically intuitive. To our knowledge, every allocation rule that has been considered in the literature for this environment satisfies these two conditions; any equilibrium outcome of a double auction certainly does $([13,23])$, as does any allocation rule that is ex ante efficient ([25]).

The first condition is that the allocation rule be almost always deterministic. This condition requires that $\mathrm{p}\left(\mathrm{v}_{1}, \mathrm{v}_{2}\right)$ almost always takes on only the values 0 or 1 , so that trade surely occurs or surely does not occur. More precisely, the deterministic condition is

(DET) $\quad\{0,1\} \supseteq \mathrm{p}\left(\mathrm{v}_{1}, \mathrm{~T}_{2}\right)$ for all $\mathrm{v}_{1}$ and almost all $\left(\mathrm{F}_{2}\right) \mathrm{v}_{2}$, and $\{0,1\} \supseteq p\left(\mathrm{~T}_{1}, \mathrm{v}_{2}\right)$ for all $\mathrm{v}_{2}$ and almost all $\left(\mathrm{F}_{1}\right) \mathrm{v}_{1}$. 
The second condition is monotonicity. It requires, first, that the probability of trade be weakly increasing in the buyer's type (value) and weakly decreasing in the seller's type (cost). (This is almost a consequence of IC: as Myerson and Satterthwaite [19] show, the two marginal probability-of-trade functions have these monotonicity characteristics.) Second, monotonicity requires that the buyer's payment be an increasing function of both players' types on the set of type pairs that trade. Formally, the monotonicity condition is

(MON) For all $\left(\mathrm{v}_{1}, \mathrm{v}_{2}\right),\left(\mathrm{u}_{1}, \mathrm{u}_{2}\right) \in \mathrm{T}_{1} \times \mathrm{T}_{2}$ :

(i) $\mathrm{p}\left(\mathrm{v}_{1}, \mathrm{v}_{2}\right) \leq \mathrm{p}\left(\mathrm{u}_{1}, \mathrm{u}_{2}\right)$ if $\mathrm{v}_{1} \geq \mathrm{u}_{1}$ and $\mathrm{v}_{2} \leq \mathrm{u}_{2}$, and

(ii) $\mathrm{x}\left(\mathrm{v}_{1}, \mathrm{v}_{2}\right) \leq \mathrm{x}\left(\mathrm{u}_{1}, \mathrm{u}_{2}\right)$ if $\left(\mathrm{v}_{1}, \mathrm{v}_{2}\right) \leq\left(\mathrm{u}_{1}, \mathrm{u}_{2}\right)$ and $\mathrm{p}\left(\mathrm{v}_{1}, \mathrm{v}_{2}\right)=\mathrm{p}\left(\mathrm{u}_{1}, \mathrm{u}_{2}\right)=1$.

Define a set of allocation rules by

$$
\left.\mathrm{A}^{* *} \equiv \text { convex hull( }\{(\mathrm{p}, \mathrm{x}) \mid \mathrm{IC}, \text { EXPIR, DET, and MON are satisfied }\}\right) .
$$

Theorem 3: $\mathrm{A}^{*} \supset \mathrm{A}^{* *}$, so that any allocation rule in $\mathrm{A}^{* *}$ is a full communication equilibrium outcome of the unmediated communication-bidding game $\Gamma(\mathrm{k})$, for any $k \in[0,1]$.

Notes on the Proof: The first step is to show that a convex combination of allocation rules in $\mathrm{A}^{*}$ is also in $\mathrm{A}^{*}$. The proof is then completed by showing that $\mathrm{IC}^{*}$ is implied by IC, EXPIR, DET, and MON. Given an allocation rule $(\mathrm{p}, \mathrm{x})$, consider a two-stage mechanism in which the traders report their values $\left(r_{1}, r_{2}\right)$ and learn of the putative allocation $\left(p\left(r_{1}, r_{2}\right), x\left(r_{1}, r_{2}\right)\right)$ in the first stage, and then they each decide whether to veto this proposed allocation, thereby enacting the no-trade allocation, in the second stage. The resulting game has an equilibrium in which the traders truthfully report their values if and only if $(p, x)$ satisfies $I C^{*}$, and $(p, x)$ is an equilibrium outcome if and only if it satisfies IC* and EXPIR. In this game there are two reasons why the seller, for example, might want to misreport his value. First, as in Example 1, misreporting may give him a chance of receiving a higher price. It is easy to show, from IC and EXPIR, that the seller will not 
want to over-report his value. Because of MON, however, under-reporting can only lower the price he receives from those types of buyer he would have traded with anyway. It remains only to rule out the second reason he might have for misreporting, which is that by so doing he may enlarge the set of buyer types with whom he can profitably trade. The difficult part of the proof is to show that the seller, if he under-reports his value, will not gain enough from the buyer types with whom he would not otherwise have traded to compensate for the lower price he obtains from the buyer types with whom he would have traded anyway.

The following simple example shows that the containment proved in Theorem 3 may be proper. In particular, it shows that allocation rules in $\mathrm{A}^{*}$ need not have monotonic payment functions.

Example 2: The seller has value $\mathrm{v}_{1}=0$ or $\mathrm{v}_{1}=1$, each with probability one-half. The buyer has value $\mathrm{v}_{2}=4$ or $\mathrm{v}_{2}=5$, each with probability one-half. The allocation rule is $(\mathrm{p}, \mathrm{x})$, the important part of which is given by
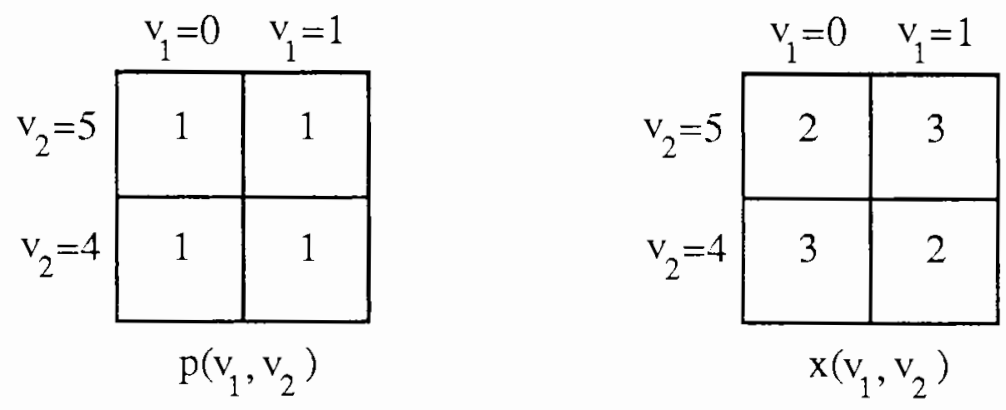

This allocation rule does not satisfy MON(ii). Yet it trivially satisfies EXPIR and IC*, and so is an equilibrium outcome of the unmediated communication-bidding game $\Gamma(\mathrm{k})$. 


\section{Concluding Remarks}

1. Our results are usefully recapped by breaking them into five propositions:

(a) the allocation rules that are outcomes of (mediated) communication-bidding games are the ones satisfying $\mathrm{IC}^{*}$ and EXPIR;

(b) any outcome of any (mediated) communication-bidding game is also an outcome of an unmediated communication-bidding game;

(c) all such allocation rules are equilibrium outcomes of a single unmediated communication-bidding game, $\Gamma(\mathrm{k})$ (recall that $\Gamma(\mathrm{k})$ is the game in which a $\mathrm{k}$-double auction is played after a simultaneously exchange of messages);

(d) all of these allocation rules are outcomes of full communication equilibria of $\Gamma(\mathrm{k})$; and

(e) the set of these allocation rules is very large, containing all convex combinations of rules satisfying IC, EXPIR, DET and MON.

We have stressed (e), as it has the most severe consequences for mechanism designers, both those who ignore the opportunities that real-world players have for conversing among themselves, and those who do not have a good equilibrium selection argument to back up their predictions. (We know of no good selection argument for this framework - see Remark 4 below.)

2. Of the results listed in Remark 1, (b) and (c) are similar to ones obtained by Forges [9] and Barany [2] for more general games.

Forges [9] shows that a "mechanism design" problem can, in a particular sense, be converted into an "equilibrium selection" problem. She considers a specific communication scheme consisting of two rounds of sequential, public announcements of messages. Her theorem states that when this scheme is used prior to the playing of any (finite) Bayesian game with at least three players, the set of correlated equilibrium outcomes of the resulting two-stage game contains all the equilibrium outcomes that could be obtained by adding any other communication mechanism. 
It is not known whether Forges' theorem extends to general games with two players. Suppose it did apply to two-person k-double auctions. We could then conclude that the set of correlated equilibrium outcomes of an unmediated communication-bidding game $\Gamma_{F}(\mathrm{k})$ defined by adding two rounds of sequential message exchange would contain the equilibrium outcomes of all other communication-bidding games $\mu(\mathrm{k})$. Instead, we proved that the set of Bayesian-Nash equilibrium outcomes of the unmediated communicationbidding game $\Gamma(\mathrm{k})$ defined by adding one round of simultaneous message exchange contains the equilibrium outcomes of all other communication-bidding games $\mu(\mathrm{k})$. Our result is stronger in so far as it does not rely on correlated equilibria (the set of correlated equilibrium outcomes of $\Gamma(\mathrm{k})$ contains its Bayesian-Nash equilibrium outcomes). (In our terminology, a correlated equilibrium is not "unmediated" because it is obtained by adding a communication mechanism that transmits, but does not receive, confidential messages - a "deaf mediator.") However, as our result relies on simultaneous rather than sequential message exchange, it does not imply that Forges' result holds for the sequential communication-bidding game $\Gamma_{\mathrm{F}}(\mathrm{k})$. (See Remark 5 below for a discussion of sequential versus simultaneous communication.)

Another related result is that of Barany [2]. Subject to some technical qualifications, this result is that any correlated equilibrium outcome of a normal form game is a Nash equilibrium outcome of a game obtained by adding a communication scheme involving "plain conversation." If the theorems of Forges and Barany both applied to our framework, the combination of his scheme with hers would be a communication mechanism that results in an unmediated communication-bidding game whose set of equilibrium outcomes contains those of all other communication-bidding games. That is, it would imply (b) and (c) above. (Barany's theorem does not actually apply to our framework. It specifically does not apply to games with only two or three players. And, it only concerns correlated equilibria in which the probabilities are rational-valued.)

3. Farrell and Gibbons [6] were the first to consider communication in a double auction. Their game is a special case or ours: each player is allowed in the message stage just two 
messages, "keen" and "not keen;" the value of each player is distributed uniformly on $[0,1]$; and only the symmetric $k=1 / 2$ double auction is considered. Most attention is devoted to the following equilibrium. Let $y=(22+12 \sqrt{2}) / 49$, which is approximately .795 . The equilibrium strategies are for the buyer to say "keen" if his value exceeds $y$, and "not keen" otherwise. The seller speaks simultaneously, saying "keen" if his value is below 1-y and "not keen" otherwise. If they both say "not keen," they play the no-trade equilibrium in the double auction. If the buyer says "keen" and the seller says "not keen," they bid according to the linear Chatterjee and Samuelson [3] strategies that are an equilibrium when their values are uniformly distributed on the intervals [y,1] and [1-y,1], respectively. Similarly, if the buyer says "not keen" and the seller says "keen," they bid according to the linear equilibrium given that their values are uniformly distributed on $[0, y]$ and $[0,1-y]$. Finally, if they both say "keen," they both bid $1 / 2$, which is the average of the highest possible value for the seller, 1-y, and the lowest possible value for the buyer when they have both said "keen" (as $\mathrm{y}>1-\mathrm{y}$, trade surely occurs in this case).

The Farrell-Gibbons equilibrium is a true communication equilibrium in the following sense: the bidding strategies played after at least some messages have been sent are a double auction equilibrium only because the messages have caused the traders to appropriately revise their beliefs about each other's type. (For example, the linear strategies played after the buyer says "keen" and the seller says "not keen" are a double auction equilibrium at that point only because the traders have revised their beliefs to be uniform distributions on $[y, 1]$ and $[1-y, 1]$.) Thus, communication in their equilibrium serves to transmit essential information.

On the other hand, the single-price strategies we use to prove Theorem 2 are double auction equilibria regardless of the traders' beliefs. The fact that they do revise their priors is irrelevant. Communication in our equilibria serves merely to ensure that the traders will play the same equilibrium of the double auction; which equilibrium they play depends upon their types. Thus, communication in our equilibria plays only a coordination role. (Of course, communication also plays a coordination role in the Farrell-Gibbons equilibrium, e.g. the message pair (not keen, not keen) guides the traders to the no-trade bidding 
strategies, which form an equilibrium to the double auction regardless of the beliefs of the traders.)

4. Single-price double auction equilibria, which are the bidding components of the equilibrium strategies of the communication-bidding game $\Gamma(\mathrm{k})$ used to prove Theorem 2 , may seem strange. They are discontinuous (but can be approximated by differentiable double auction equilibria - see [23]), and the submitting of outrageously optimistic bids, $a_{1}$ for the buyer and $b_{2}$ for the seller, may seem unreasonable (although, as long as $a_{1} \leq a_{2}$ and $\mathrm{b}_{1} \leq \mathrm{b}_{2}$, these bids are not dominated). However, there are reasons to favor single-price equilibria. First, they are easy to calculate, since they are step functions with only two steps, and do not depend upon the traders' beliefs. Second, experimental subjects experienced in the play of double auctions seem to play single-price equilibria (Radner and Schotter [21]). Third, a single-price double auction equilibrium resembles a classical Walrasian equilibrium, since in both all realized trades occur at a single price that does not depend upon the actual reservation values of the traders (assuming they are inframarginal). Fourth, if the bids in a single-price equilibrium do not induce trade, a price at which trade would be mutually beneficial is never common knowledge, so that the commitment to not renegotiate is not as severely tested as it is in, e.g., any equilibrium with invertable bidding strategies.

Of course, this last property is not true of the complete equilibrium strategies of the communication-bidding game $\Gamma(\mathrm{k})$ used to prove Theorem 2 . Since those strategies constitute a full communication equilibrium, the traders know each other's values when they play the double auction. If the specified double auction equilibrium is the no-trade equilibrium but the buyer's value is greater than the seller's, the traders will know, at the time they submit their bids, that they could do better by switching to another equilibrium in which they do trade. Nevertheless, the equilibria of $\Gamma(\mathrm{k})$ used to prove Theorem 2 are reasonable in currently accepted senses: they do not entail the use of dominated strategies, and they are sequentially rational and sequentially perfect (Grossman and Perry [10]). 
5. We do not feel that unmediated communication is appropriately modelled as a one-shot, simultaneous exchange of messages. In most oral, face-to-face situations, communication is sequential, i.e., only one player talks at a time. Furthermore, communication usually entails multiple rounds of message exchange. Typically, when a communication process occurs before the play of a mechanism, the set of equilibrium outcomes depends on whether the communication process has multiple rounds and on whether message exchange is simultaneous (see [8] or [15] for examples).

Altering the unmediated communication-bidding game $\Gamma(\mathrm{k})$ by adding more rounds of simultaneous message exchange would not change any results. No new equilibrium outcomes would be added, since the original $\Gamma(\mathrm{k})$ already has the largest set of equilibrium outcomes, $\mathrm{A}^{*}$, that could possibly be achieved by adding any communication mechanism to a k-double auction. And no equilibrium outcomes would be subtracted by adding more rounds, since any equilibrium of the original game is equivalent to an equilibrium in the game with multiple rounds in which all types of both traders send babbling messages (which are ignored) after the first round.

On the other hand, making the message exchange sequential in $\Gamma(\mathrm{k})$ would change the results: no longer would every allocation rule in $A^{*}$ be an equilibrium outcome. Such an allocation rule is that in Example 2. According to it, trade always occurs - only the price is determined by the traders' types. Suppose, to be concrete, that the buyer is designated as the first to send a message, and that the seller's return message is the last message sent. Assume, by way of contradiction, that the allocation rule $(\mathrm{p}, \mathrm{x})$ of Example 2 is an equilibrium outcome. The seller's equilibrium strategy, regardless of his type, must be to respond to any message of the buyer's with a message guaranteeing that the ensuing double auction equilibrium is that which yields the highest possible expected price given the buyer's message (the seller cares only about the price because, by assumption, trade surely occurs regardless of the messages). The expected price therefore cannot depend upon the seller's type, contrary to the specification of $(p, x)$.

Thus, we feel that the largest caveat to our results is that the assumption of simultaneous message exchange is not as realistic as sequential message exchange, and that 
the latter eliminates some of the outcomes achieved by the former. The characterization of the set of equilibrium outcomes of an unmediated, sequential communication-bidding game is an open problem. (We note, however, that the buyer's best allocation rule will remain an equilibrium outcome. Recall that only the buyer sends a message in the equilibrium that generates it, as described in Section 3. This equilibrium can be duplicated in a game with sequential communication by having all messages except for the buyer's first message be babbling messages that are ignored by their receiver. Naturally, the seller's best allocation rule can be similarly obtained.)

6. Another open question concerns the welfare comparison of $\mathrm{A}$ to $\mathrm{A}^{*}$. That is, how does the set of outcomes obtained from arbitrary (voluntary) mechanisms compare, in utility terms, to the set of outcomes obtained when (simultaneous) communication is added to a double auction? Because distinct allocation rules can yield the same pair of interim utility functions, $U_{1}\left(v_{1}, v_{1}\right)$ and $U_{2}\left(v_{2}, v_{2}\right)$, a pair of interim utility functions generated by an allocation rule in $\mathrm{A}$, but not $\mathrm{A}^{*}$, may also be generated by a rule in $\mathrm{A}^{*}$. It would be quite interesting to characterize the class of rules in $A$ for which rules in $A^{*}$ exist that yield the same interim utility functions. It would be most interesting if the efficient allocation rules in A were in this class. For then, we would know that a double auction with unmediated communication can, in some of its equilibria, achieve all the same levels of welfare as can general (voluntary) mechanisms.

We know an answer to this last question when both values are uniformly distributed on $[0,1]$. Satterthwaite and Williams [23] establish the following result for this case: given any utility pair on the frontier of the ex ante utility possibility set generated by A, a number $k^{\prime} \in[0,1]$ exists such that the linear equilibrium of the double auction $D\left(k^{\prime}\right)$ gives the traders those ex ante utility levels. (This does not hold for generic distributions, as Satterthwaite and Williams also show.) Since the equilibrium outcomes of double auctions satisfy IC, EXPIR, DET, and MON, they are in $\mathrm{A}^{*}$ by Theorem 3. Hence, for any fixed $\mathrm{k} \in[0,1]$, every ex ante efficient allocation rule in $\mathrm{A}$ is an equilibrium outcome of the unmediated communication-bidding game $\Gamma(\mathrm{k})$. 
7. We conclude by remarking that the properties of allocation rules that we have been concerned with, IC ${ }^{*}$ and EXPIR, should be of interest in more general contexts. Recall that an allocation rule satisfies these properties if it is an equilibrium outcome of some multi-stage game in which, in the last stage, each trader learns of the proposed allocation and has the ability to enact instead the no-trade allocation. Such ex post veto power is not uncommon. For example, it is often impossible, and known to be impossible, to specify in a contract all contingencies so completely as to prevent a party from essentially reneging on the contract whenever not reneging would lead to a loss ([12]). In this case, credible contractual agreements must satisfy appropriate generalizations of IC* and EXPIR. 


\section{Appendix}

This Appendix contains the formal proofs. They make use of the indicator function $1_{\{c \leq d\}}$, which takes the value 1 if $c \leq d$ and 0 otherwise.

Theorem 1: $\mathrm{A}^{*}$ contains all equilibrium outcomes of any communication-bidding game $\mu(k)$, for any $k \in[0,1]$.

Proof: Let $(p, x)$ be an equilibrium outcome of a communication-bidding game $\mu(k)$. By the general revelation principle, we can assume the mechanism is a revelation-suggestion mechanism in which honest reporting and obedient bidding is an equilibrium. Formally, this mechanism is a function $\delta(\cdot \mid \cdot)$, where $\delta\left(\cdot \mid \mathrm{r}_{1}, \mathrm{r}_{2}\right)$ is a distribution on suggested bids $\left(\beta_{1}, \beta_{2}\right)$ for each pair $\left(r_{1}, r_{2}\right) \in T_{1} \times T_{2}$ of reported types. Let ${\widetilde{\beta_{i}}}_{i}$ and $\widetilde{r}_{i}$ be the random bids and reported types in the obedient and honest equilibrium. Thus, $\widetilde{\mathrm{r}}_{1}=\widetilde{\mathrm{v}}_{1}, \widetilde{\mathrm{r}}_{2}=\widetilde{\mathrm{v}}_{2}$, and $\delta\left(\cdot \mid \mathrm{r}_{1}, \mathrm{r}_{2}\right)$ is the distribution of $\left(\widetilde{\beta}_{1}, \widetilde{\beta}_{2}\right)$ conditional on $\left(\widetilde{\mathrm{r}}_{1}, \widetilde{\mathrm{r}}_{2}\right)=\left(\mathrm{r}_{1}, \mathrm{r}_{2}\right)$.

We now prove that $(\mathrm{p}, \mathrm{x})$ satisfies EXPIR for the seller (EXPIR for the buyer is proved similarly). Recall from Section 2 that in our definition of an equilibrium, no seller type submits a bid less than his value. Hence, $\widetilde{\beta_{1}} \geq v_{1}$ always. This implies EXPIR: for any $\left(\mathrm{v}_{1}, \mathrm{v}_{2}\right)$,

$$
\begin{aligned}
\mathrm{x}\left(\mathrm{v}_{1}, \mathrm{v}_{2}\right)-\mathrm{v}_{1} \mathrm{p}\left(\mathrm{v}_{1}, \mathrm{v}_{2}\right) & =\mathrm{E}\left[\left[k \tilde{\beta}_{2}+(1-\mathrm{k}) \tilde{\beta}_{1}-\mathrm{v}_{1}\right] 1_{\left\{\tilde{\beta}_{1} \leq \tilde{\beta}_{2}\right\}} \mid \tilde{\mathrm{r}}_{1}=\mathrm{v}_{1}, \tilde{\mathrm{r}}_{2}=\mathrm{v}_{2}\right] \\
& \geq \mathrm{E}\left[\left[\mathrm{k} \tilde{\beta}_{2}+(1-\mathrm{k}) \mathrm{v}_{1}-\mathrm{v}_{1}\right] 1_{\left\{\tilde{\beta}_{1} \leq \tilde{\beta}_{2}\right\}} \mid \tilde{\mathrm{r}}_{1}=\mathrm{v}_{1}, \tilde{\mathrm{r}}_{2}=\mathrm{v}_{2}\right] \\
& \geq 0 .
\end{aligned}
$$

We now prove that $(p, x)$ satisfies $I C^{*}$ for the seller (a similar proof works for the buyer). Suppose a type $v_{1}$ seller reports dishonestly that he is of type $r_{1}$, but then bids obediently as long as the suggested bid is no less than $v_{1}$, in which case he bids $v_{1}$. His expected utility from following this strategy is no greater than his equilibrium expected utility, $\mathrm{U}_{1}\left(\mathrm{v}_{1}, \mathrm{v}_{1}\right)$. Hence, 
(10)

$$
\begin{aligned}
& \mathrm{U}_{1}\left(\mathrm{v}_{1}, \mathrm{v}_{1}\right) \geq \mathrm{E}\left[\left[\mathrm{k} \tilde{\beta}_{2}+(1-\mathrm{k}) \max \left(\mathrm{v}_{1}, \tilde{\beta}_{1}\right)-\mathrm{v}_{1}\right] 1_{\left\{\max \left(\mathrm{v}_{1}, \tilde{\beta}_{1}\right) \leq \tilde{\beta}_{2}\right\}} \mid \tilde{\mathrm{r}}_{1}=\mathrm{r}_{1}\right] \\
& =\mathrm{E}\left\{\mathrm{E}\left[\left[\mathrm{k} \tilde{\beta}_{2}+(1-\mathrm{k}) \max \left(\mathrm{v}_{1}, \tilde{\beta}_{1}\right)-\mathrm{v}_{1}\right] 1_{\left\{\max \left(\mathrm{v}_{1}, \tilde{\beta}_{1}\right) \leq \tilde{\beta}_{2}\right\}} \mid \widetilde{\mathrm{r}}_{2}, \widetilde{\mathrm{r}}_{1}=\mathrm{r}_{1}\right] \mid \tilde{\mathrm{r}}_{1}=\mathrm{r}_{1}\right\} .
\end{aligned}
$$

For each $\widetilde{\mathrm{r}}_{2}$,

$$
\begin{aligned}
& \mathrm{E}\left[\left[\mathrm{k} \widetilde{\beta}_{2}+(1-\mathrm{k}) \max \left(\mathrm{v}_{1}, \widetilde{\beta}_{1}\right)-\mathrm{v}_{1}\right] 1_{\left\{\max \left(\mathrm{v}_{1}, \tilde{\beta}_{1}\right) \leq \tilde{\beta}_{2}\right\}} \mid \widetilde{\mathrm{r}}_{2}, \widetilde{\mathrm{r}}_{1}=\mathrm{r}_{1}\right] \\
& \geq E\left[\left[k \tilde{\beta}_{2}+(1-k) \tilde{\beta}_{1}-v_{1}\right] 1_{\left\{\tilde{\beta}_{1} \leq \tilde{\beta}_{2}\right\}} \mid \tilde{r}_{2}, \tilde{r}_{1}=r_{1}\right] \\
& =\mathrm{x}\left(\mathrm{r}_{1}, \widetilde{\mathrm{r}}_{2}\right)-\mathrm{v}_{1} \mathrm{p}\left(\mathrm{r}_{1}, \widetilde{\mathrm{r}}_{2}\right) \\
& =\mathrm{x}\left(\mathrm{r}_{1}, \tilde{\mathrm{v}}_{2}\right)-\mathrm{v}_{1} \mathrm{p}\left(\mathrm{r}_{1}, \widetilde{\mathrm{v}}_{2}\right) .
\end{aligned}
$$

Also,

$$
\mathrm{E}\left[\left[\mathrm{k} \tilde{\beta}_{2}+(1-\mathrm{k}) \max \left(\mathrm{v}_{1}, \tilde{\beta}_{1}\right)-\mathrm{v}_{1}\right] 1_{\left\{\max \left(\mathrm{v}_{1}, \tilde{\beta}_{1}\right) \leq \tilde{\beta}_{2}\right\}} \mid \tilde{\mathrm{r}}_{2}, \tilde{\mathrm{r}}_{1}=\mathrm{r}_{1}\right] \geq 0
$$

Putting (11) and (12) into (10) yields:

$$
\begin{aligned}
\mathrm{U}_{1}\left(\mathrm{v}_{1}, \mathrm{v}_{1}\right) & \geq \mathrm{E}\left\{\max \left\{0, \mathrm{x}\left(\mathrm{r}_{1}, \widetilde{\mathrm{v}}_{2}\right)-\mathrm{v}_{1} \mathrm{p}\left(\mathrm{r}_{1}, \widetilde{\mathrm{v}}_{2}\right)\right\} \mid \widetilde{\mathrm{r}}_{1}=\mathrm{r}_{1}\right\} \\
& =\mathrm{E}\left\{\max \left\{0, \mathrm{x}\left(\mathrm{r}_{1}, \widetilde{\mathrm{v}}_{2}\right)-\mathrm{v}_{1} p\left(\mathrm{r}_{1}, \widetilde{\mathrm{v}}_{2}\right)\right\} \mid \widetilde{\mathrm{v}}_{1}=\mathrm{r}_{1}\right\} \\
& =\mathrm{U}_{1}^{*}\left(\mathrm{r}_{1}, \mathrm{v}_{1}\right) .
\end{aligned}
$$

Thus, $(p, x)$ satisfies $I^{*}\left(a s U_{1}^{*}\left(v_{1}, v_{1}\right)=U_{1}\left(v_{1}, v_{1}\right)\right.$, by EXPIR). So $(p, x) \in A^{*}$. Q.E.D.

Theorem 2: $A^{*}$ is the set of full communication equilibrium outcomes of the unmediated communication-bidding game $\Gamma(\mathrm{k})$, for any $\mathrm{k} \in[0,1]$,

Proof: From Theorem 1, all full communication equilibrium outcomes of $\Gamma(\mathrm{k})$ are in $\mathrm{A}^{*}$. So let $(p, x) \in A^{*}$. We construct an equilibrium with outcome $(p, x)$. 
As a preliminary, define the binary matching function $\varphi:[0,1]^{2} \rightarrow[0,1]$ in the following way. Given two numbers $y_{1}$ and $y_{2}$ in $[0,1]$, let $\varphi\left(y_{1}, y_{2}\right)$ be the number whose binary expansion has a " 1 " in the $\mathrm{n}^{\mathrm{th}}$ position if and only if the binary expansion of $\mathrm{y}_{1}$ has the same digit in its $n^{\text {th }}$ position as does the binary expansion of $y_{2}$. Note that if $y_{1}$ and $y_{2}$ are independent random variables on $[0,1]$, and one of them has a uniform distribution, then $\varphi\left(\mathrm{y}_{1}, \mathrm{y}_{2}\right)$ is also a uniformly distributed random variable on $[0,1]$.

The equilibrium strategy pair that achieves $(\mathrm{p}, \mathrm{x})$ is as follows. The behavioral strategy of trader $i$ in the message stage is to announce truthfully his type, and to announce the realization $y_{i}$ of a number he has drawn at random from a uniform distribution on $[0,1]$. In the bidding stage, if $\varphi\left(y_{1}, y_{2}\right)<p\left(v_{1}, v_{2}\right)$ or $p\left(v_{1}, v_{2}\right)=1$ (these $v_{i}$ 's and $y_{i}$ 's are the announcements made in the message stage), the buyer and seller play the single-price equilibrium $\left(\beta_{1}^{z}, \beta_{2}^{z}\right)$ of the double auction game $D(k)$, with the price $z$ given by $\mathrm{z}=\mathrm{x}\left(\mathrm{v}_{1}, \mathrm{v}_{2}\right) / \mathrm{p}\left(\mathrm{v}_{1}, \mathrm{v}_{2}\right)$. If $\varphi\left(\mathrm{y}_{1}, \mathrm{y}_{2}\right) \geq \mathrm{p}\left(\mathrm{v}_{1}, \mathrm{v}_{2}\right)$ or $\mathrm{p}\left(\mathrm{v}_{1}, \mathrm{v}_{2}\right)=0$, then the no-trade equilibrium of $D(k)$ is played, which is defined by all types of buyer bidding $a_{1}$ and all types of seller bidding $b_{2}$. (The random drawings of $y_{1}$ and $y_{2}$ in the message stage can be dispensed with if $\mathrm{p}\left(\mathrm{v}_{1}, \mathrm{v}_{2}\right) \in\{0,1\}$ for all $\left(\mathrm{v}_{1}, \mathrm{v}_{2}\right)$.)

We now show that $(\mathrm{p}, \mathrm{x})$ is the outcome of these strategies. For a given realization of values $\left(\mathrm{v}_{1}, \mathrm{v}_{2}\right)$, the constructed strategies lead to the no-trade equilibrium of $\mathrm{D}(\mathrm{k})$ with probability $1-\mathrm{p}\left(\mathrm{v}_{1}, \mathrm{v}_{2}\right)$, and to a single-price equilibrium with probability $\mathrm{p}\left(\mathrm{v}_{1}, \mathrm{v}_{2}\right)$. If trade always occurs in this single-price equilibrium, then, as the price in it is $\mathrm{z}=\mathrm{x}\left(\mathrm{v}_{1}, \mathrm{v}_{2}\right) / \mathrm{p}\left(\mathrm{v}_{1}, \mathrm{v}_{2}\right)$, the resulting allocation will be $\left(\mathrm{p}\left(\mathrm{v}_{1}, \mathrm{v}_{2}\right), \mathrm{x}_{(}\left(\mathrm{v}_{1}, \mathrm{v}_{2}\right)\right)$. Trade does always occur in this single-price equilibrium: EXPIR implies that $\mathrm{v}_{1} \leq \mathrm{z} \leq \mathrm{v}_{2}$, so that both traders will submit the bid $z$. Thus, $(p, x)$ is the outcome.

We now show that these strategies are a (perfect Bayesian) equilibrium of $\Gamma(k)$. Since the single-price strategies and the no-trade strategies are equilibria of any double auction regardless of the beliefs of the traders about each other's value, the traders' strategies are a best reply to each other in the bidding stage. In the message stage, trader $\mathrm{i}$ is content to draw his $y_{i}$ from a uniform distribution because, given that the other trader is drawing from a uniform distribution, his choice of $y_{i}$ cannot influence the distribution of 
$\varphi\left(\mathrm{y}_{1}, \mathrm{y}_{2}\right)$. So, it remains only to show that the traders are content to truthfully announce their values. Consider the seller (the argument for the buyer is similar). Suppose he reports $r_{1}$ when his type is $v_{1}$, and that he learns the buyer's type is $\widetilde{v}_{2}$ in the message stage. Then, depending upon the realization of $\varphi\left(y_{1}, y_{2}\right)$, in the bidding stage he will play the no-trade equilibrium with probability $1-\mathrm{p}\left(\mathrm{r}_{1}, \tilde{\mathrm{v}}_{2}\right)$, and the $\tilde{\mathrm{z}}=\mathrm{x}\left(\mathrm{r}_{1}, \widetilde{\mathrm{v}}_{2}\right) / \mathrm{p}\left(\mathrm{r}_{1}, \widetilde{\mathrm{v}}_{2}\right)$ single-price equilibrium with probability $\mathrm{p}\left(\mathrm{r}_{1}, \widetilde{\mathrm{v}}_{2}\right)$. The best he can do in the no-trade equilibrium gains him zero utility. The best he can do in the single-price equilibrium is either to bid $\tilde{z}$ and so trade for the price $\tilde{z}$, or to submit a higher bid to insure no-trade and gain zero utility. Thus, his expected utility conditional on $\tilde{v}_{2}$ if he claims his type is $r_{1}$ is

$$
\mathrm{p}\left(\mathrm{r}_{1}, \widetilde{\mathrm{v}}_{2}\right)\left[\max \left\{0, \widetilde{\mathrm{z}}-\mathrm{v}_{1}\right\}\right]+\left(1-\mathrm{p}\left(\mathrm{r}_{1}, \widetilde{\mathrm{v}}_{2}\right)\right)[0]=\max \left\{0, \mathrm{x}\left(\mathrm{r}_{1}, \widetilde{\mathrm{v}}_{2}\right)-\mathrm{v}_{1} \mathrm{p}\left(\mathrm{r}_{1}, \widetilde{\mathrm{v}}_{2}\right)\right\}
$$

Thus, $\mathrm{IC}^{*}$ implies that reporting truthfully, $\mathrm{r}_{1}=\mathrm{v}_{1}$, is optimal for him. Q.E.D.

The proof of Theorem 3 requires two lemmas.

Lemma 1: The set $A^{*}$ is convex.

Proof: Let $\left(\mathrm{p}^{\prime}, \mathrm{x}^{\prime}\right) \in \mathrm{A}^{*}$ and $\left(\mathrm{p}^{\prime \prime}, \mathrm{x}^{\prime \prime}\right) \in \mathrm{A}^{*}$, so that both satisfy $\mathrm{IC}^{*}$ and EXPIR. Let $(\mathrm{p}, \mathrm{x})=\lambda\left(\mathrm{p}^{\prime}, \mathrm{x}^{\prime}\right)+(1-\lambda)\left(\mathrm{p}^{\prime \prime}, \mathrm{x}^{\prime \prime}\right)$, where $\lambda \in[0,1] . \quad$ As EXPIR is a set of linear inequalities, $(p, x)$ satisfies EXPIR. Thus, for any $v_{1} \in T_{1}$ and $r_{1} \in T_{1}$,

$$
\begin{aligned}
\mathrm{E} & {\left[\max \left\{0, \mathrm{x}\left(\mathrm{v}_{1}, \widetilde{\mathrm{v}}_{2}\right)-\mathrm{v}_{1} \mathrm{p}\left(\mathrm{v}_{1}, \tilde{\mathrm{v}}_{2}\right)\right\}\right]=\mathrm{E}\left[\mathrm{x}\left(\mathrm{v}_{1}, \widetilde{\mathrm{v}}_{2}\right)-\mathrm{v}_{1} \mathrm{p}\left(\mathrm{v}_{1}, \tilde{\mathrm{v}}_{2}\right)\right] } \\
& =\lambda \mathrm{E}\left[\mathrm{x}^{\prime}\left(\mathrm{v}_{1}, \widetilde{\mathrm{v}}_{2}\right)-\mathrm{v}_{1} \mathrm{p}^{\prime}\left(\mathrm{v}_{1}, \widetilde{\mathrm{v}}_{2}\right)\right]+(1-\lambda) \mathrm{E}\left[\mathrm{x}^{\prime \prime}\left(\mathrm{v}_{1}, \widetilde{\mathrm{v}}_{2}\right)-\mathrm{v}_{1} \mathrm{p}^{\prime \prime}\left(\mathrm{v}_{1}, \widetilde{\mathrm{v}}_{2}\right)\right] \\
& =\lambda \mathrm{E}\left[\max \left\{0, \mathrm{x}^{\prime}\left(\mathrm{v}_{1}, \widetilde{\mathrm{v}}_{2}\right)-\mathrm{v}_{1} \mathrm{p}^{\prime}\left(\mathrm{v}_{1}, \widetilde{\mathrm{v}}_{2}\right)\right\}\right]+(1-\lambda) \mathrm{E}\left[\max \left\{0, \mathrm{x}^{\prime \prime}\left(\mathrm{v}_{1}, \widetilde{\mathrm{v}}_{2}\right)-\mathrm{v}_{1} \mathrm{p}^{\prime \prime}\left(\mathrm{v}_{1}, \widetilde{\mathrm{v}}_{2}\right)\right\}\right] \\
& \geq \lambda \mathrm{E}\left[\max \left\{0, \mathrm{x}^{\prime}\left(\mathrm{r}_{1}, \widetilde{\mathrm{v}}_{2}\right)-\mathrm{v}_{1} \mathrm{p}^{\prime}\left(\mathrm{r}_{1}, \widetilde{\mathrm{v}}_{2}\right)\right\}\right]+(1-\lambda) \mathrm{E}\left[\max \left\{0, \mathrm{x}^{\prime \prime}\left(\mathrm{r}_{1}, \widetilde{\mathrm{v}}_{2}\right)-\mathrm{v}_{1} \mathrm{p}^{\prime \prime}\left(\mathrm{r}_{1}, \widetilde{\mathrm{v}}_{2}\right)\right\}\right] \\
& \geq \mathrm{E}\left[\max \left\{0, \mathrm{x}\left(\mathrm{r}_{1}, \widetilde{\mathrm{v}}_{2}\right)-\mathrm{v}_{1} \mathrm{p}\left(\mathrm{r}_{1}, \tilde{\mathrm{v}}_{2}\right)\right\}\right] .
\end{aligned}
$$

So $\mathrm{IC}^{*}$ holds for the seller; the proof is similar for the buyer. Hence, $(\mathrm{p}, \mathrm{x}) \in \mathrm{A}^{*}$. Q.E.D. 
The following lemma, and the proof of Theorem 3 to come, are put only in terms of the seller - as usual, symmetric arguments hold for the buyer. To simplify notation, we henceforth drop the subscript "1" on the type variable of the seller. Further notation is also needed. Given an allocation rule $(p, x)$, the expected allocation meant for any type $v \in T_{1}$ is $\left(\mathrm{p}_{1}(\mathrm{v}), \mathrm{x}_{1}(\mathrm{v})\right)$, where $\mathrm{p}_{1}$ and $\mathrm{x}_{2}$ are the marginal probability-of-trade and payment functions:

$$
\mathrm{p}_{1}(\mathrm{v}) \equiv \mathrm{E}\left[\mathrm{p}\left(\mathrm{v}, \widetilde{\mathrm{v}}_{2}\right)\right] \quad \text { and } \quad \mathrm{x}_{1}(\mathrm{v}) \equiv \mathrm{E}\left[\mathrm{x}\left(\mathrm{v}, \tilde{\mathrm{v}}_{2}\right)\right]
$$

Also for the given allocation rule, define two functions on $T_{1} \times T_{1}$ by

$$
\begin{aligned}
& \hat{\mathrm{p}}(\mathrm{r}, \mathrm{v}) \equiv \mathrm{E}\left[\mathrm{p}\left(\mathrm{r}, \tilde{\mathrm{v}}_{2}\right) 1_{\left\{\mathrm{x}\left(\mathrm{r}, \tilde{\mathrm{v}}_{2}\right)>\mathrm{vp}\left(\mathrm{r}, \tilde{\mathrm{v}}_{2}\right)\right\}}\right] \text {, and } \\
& \hat{\mathrm{x}}(\mathrm{r}, \mathrm{v}) \equiv \mathrm{E}\left[\mathrm{x}\left(\mathrm{r}, \tilde{\mathrm{v}}_{2}\right) 1_{\left\{\mathrm{x}\left(\mathrm{r}, \tilde{\mathrm{v}}_{2}\right)>\mathrm{vp}\left(\mathrm{r}, \tilde{\mathrm{v}}_{2}\right)\right\}}\right] .
\end{aligned}
$$

Then $U_{1}^{*}(r, v)$, the expected utility of type $v$ when he reports that his type is $r$ and he can reject any allocation that gives him nonpositive utility ex post, is given by

$$
\begin{aligned}
\mathrm{U}_{1}^{*}(\mathrm{r}, \mathrm{v}) & =\mathrm{E}\left[\max \left\{0, \mathrm{x}\left(\mathrm{r}, \tilde{\mathrm{v}}_{2}\right)-\mathrm{vp}\left(\mathrm{r}, \tilde{\mathrm{v}}_{2}\right)\right\}\right] \\
& =\mathrm{E}\left[\left[\mathrm{x}\left(\mathrm{r}, \tilde{\mathrm{v}}_{2}\right)-\mathrm{vp}\left(\mathrm{r}, \tilde{\mathrm{v}}_{2}\right)\right] 1_{\left\{\mathrm{x}\left(\mathrm{r}, \tilde{\mathrm{v}}_{2}\right)>\mathrm{vp}\left(\mathrm{r}, \tilde{\mathrm{v}}_{2}\right)\right\}}\right] \\
& =\hat{x}(\mathrm{r}, \mathrm{v})-\mathrm{vp}(\mathrm{r}, \mathrm{v}) .
\end{aligned}
$$

That is, $(\hat{p}(r, v), \hat{x}(r, v))$ is the best (expected) allocation that type $v$ can receive by reporting that his type is $r$.

Lemma 2: If $(p, x)$ is an allocation rule satisfying IC and EXPIR, but not IC* (for the seller), then types $r<v<\hat{v}$ in $T_{1}$ exist such that

(i) $U_{1}(v, v)<\hat{x}(r, \hat{v})-v \hat{p}(r, \hat{v})$, and

(ii) $\hat{\mathrm{p}}(\mathrm{r}, \hat{\mathrm{v}})<\mathrm{p}_{1}(\mathrm{v})$

Proof: Let $\hat{v}$ be a seller type for whom $I C^{*}$ is violated. Hence, for some $r \neq \hat{v}$, $U_{1}^{*}(r, \hat{v})>U_{1}^{*}(\hat{v}, \hat{v})$. Thus $U_{1}^{*}(r, \hat{v})>U_{1}(\hat{v}, \hat{v})$, since EXPIR implies $U_{1}^{*}(\hat{v}, \hat{v})=U_{1}(\hat{v}, \hat{v})$. Define 
$\hat{p} \equiv \hat{p}(r, \hat{v})$ and $\hat{x} \equiv \hat{x}(r, \hat{v})$. From $(15), \hat{x}-\hat{v} \hat{p}>U_{1}(\hat{v}, \hat{v})$. Hence, defining a function $\Delta$ on $\mathrm{T}_{1}$ by

$$
\Delta(\mathrm{v}) \equiv \hat{\mathrm{x}}-\mathrm{v} \hat{\mathrm{p}}-\mathrm{U}_{1}(\mathrm{v}, \mathrm{v})
$$

we have $\Delta(\hat{v})>0$.

From $\mathrm{IC}, \mathrm{U}_{1}(\hat{\mathrm{v}}, \hat{\mathrm{v}}) \geq \mathrm{U}_{1}(\mathrm{r}, \hat{\mathrm{v}})$, which gives $\mathrm{U}_{1}^{*}(\mathrm{r}, \hat{\mathrm{v}})>\mathrm{U}_{1}(\mathrm{r}, \hat{\mathrm{v}})$. Some $\mathrm{v}_{2}$ therefore exists such that $x\left(r, v_{2}\right)-\hat{v} p\left(r, v_{2}\right)<0$ (otherwise, $\left.U_{1}^{*}(r, \hat{v})=U_{1}(r, \hat{v})\right)$. Combining this with EXPIR, we get

$$
\hat{v} \mathrm{p}\left(\mathrm{r}, \mathrm{v}_{2}\right)>\mathrm{x}\left(\mathrm{r}, \mathrm{v}_{2}\right) \geq \mathrm{rp}\left(\mathrm{r}, \mathrm{v}_{2}\right)
$$

Hence, $\hat{v}>r$.

Consider the behavior of $\Delta$ on $[r, \hat{v}]$. We know that $\Delta(\hat{v})>0$. From EXPIR,

$$
\begin{aligned}
\Delta(r) & =\hat{x}-r \hat{p}-U_{1}(r, r) \\
& =E\left[\left[x\left(r, \tilde{v}_{2}\right)-r p\left(r, \tilde{v}_{2}\right)\right] 1_{\left\{x\left(r, \tilde{v}_{2}\right)>\hat{v} p\left(r, \tilde{v}_{2}\right)\right]}\right]-E\left[\left[x\left(r, \tilde{v}_{2}\right)-r p\left(r, \tilde{v}_{2}\right)\right]\right] \\
& \leq 0 .
\end{aligned}
$$

Now, IC implies that $\mathrm{U}_{1}(\mathrm{v}, \mathrm{v})$ is continuous in $\mathrm{v}$ (see, e.g., [19]; the proof holds even for discontinuous distributions $F_{1}$ and $F_{2}$, since the allocation rule can always be defined, in an IC way, on a cross-product of intervals.) Hence, $\Delta$ is continuous. Therefore, as $\Delta(r) \leq 0<\Delta(\hat{v})$, we conclude that for some $v \in(r, \hat{v}), \quad 0<\Delta(v)<\Delta(\hat{v})$.

Part (i) of the lemma is a restatement of $0<\Delta(v)$. Writing out $\Delta(v)<\Delta(\hat{v})$ gives

$$
(\hat{x}-v \hat{p})-\left(x_{1}(v)-v p_{1}(v)\right)<(\hat{x}-\hat{v} \hat{p})-\left(x_{1}(\hat{v})-\hat{v} p_{1}(\hat{v})\right)
$$

which, rearranging, is

$$
(\hat{v}-v) \hat{p}<x_{1}(v)-x_{1}(\hat{v})-v p_{1}(v)+\hat{v p}_{1}(\hat{v})
$$

From $I C, U_{1}(\hat{v}, \hat{v}) \geq U_{1}(v, \hat{v})$, so that $\left.x_{1}(v)-x_{1}(\hat{v}) \leq \hat{v} p_{1}(v)-\hat{v} p_{1}(\hat{v})\right)$. Substituting this into (17) and using $v<\hat{v}$ yields part (ii) of the lemma. Q.E.D. 
Theorem 3: $\mathrm{A}^{*} \supset \mathrm{A}^{* *}$, i.e., $\mathrm{IC}^{*}$ is satisfied by any convex combination of allocation rules that each satisfy IC, EXPIR, DET, and MON.

Proof: In view of Lemma 1, we need show only that a given allocation rule ( $\mathrm{p}, \mathrm{x}$ ) satisfying IC, EXPIR, DET, and MON also satisfies IC*. As usual, we only show that $(p, x)$ satisfies $I^{*}$ for the seller. To save on notation, we continue to drop the subscript " 1 " on the type variable of the seller.

Assume $(\mathrm{p}, \mathrm{x})$ violates $\mathrm{IC}^{*}$ for the seller. Then, seller types $\mathrm{r}<\mathrm{v}<\hat{\mathrm{v}}$ exist satisfying Lemma 2. Observe that

$$
\begin{aligned}
& \mathrm{U}_{1}(\mathrm{v}, \mathrm{v})=\mathrm{E}\left[\left[\mathrm{x}\left(\mathrm{v}, \tilde{\mathrm{v}}_{2}\right)-\mathrm{v}\right] 1_{\left\{\mathrm{p}\left(\mathrm{v}, \tilde{\mathrm{v}}_{2}\right)=1\right\}}\right] \\
& \left.\geq E\left[\left[x\left(v, \tilde{v}_{2}\right)-v\right] 1_{\left\{p\left(v, \tilde{v}_{2}\right)=1\right\}}\right\}_{\left\{p\left(r, \tilde{v}_{2}\right)=1\right\}}{ }^{1}\left\{x\left(r, \tilde{v}_{2}\right)>\hat{v}_{p}\left(r, \tilde{v}_{2}\right)\right\}\right] \\
& \geq E\left[\left[x\left(r, \tilde{v}_{2}\right)-v\right]{ }_{\left\{p\left(v, \tilde{v}_{2}\right)=1\right\}}^{1}\left\{p\left(r, \tilde{v}_{2}\right)=1\right\}{ }^{1}\left\{x\left(r, \tilde{v}_{2}\right)>\hat{v} p\left(r, \tilde{v}_{2}\right)\right\},\right.
\end{aligned}
$$

where the equality follows from DET and EXPIR (EXPIR implies that $x\left(v, \widetilde{v}_{2}\right)=0$ if $\left.\mathrm{p}\left(\mathrm{v}, \tilde{\mathrm{v}}_{2}\right)=0\right)$; the first inequality follows from EXPIR; and the second inequality follows from $M O N(i i)$ (using $r<v$ ). Because EXPIR implies that $x=0$ if $p=0$,

$$
\left\{v_{2} \in T_{2} \mid p\left(r, v_{2}\right)=1\right\} \supseteq\left\{v_{2} \in T_{2} \mid x\left(r, v_{2}\right)>\hat{v} p\left(r, v_{2}\right)\right\}
$$

Now we show the following inclusion:

$$
\left\{\mathrm{v}_{2} \in \mathrm{T}_{2} \mid \mathrm{p}\left(\mathrm{v}, \mathrm{v}_{2}\right)=1\right\} \supseteq\left\{\mathrm{v}_{2} \in \mathrm{T}_{2} \mid \mathrm{x}\left(\mathrm{r}, \mathrm{v}_{2}\right)>\hat{\mathrm{v} p}\left(\mathrm{r}, \mathrm{v}_{2}\right)\right\}
$$

If $(20)$ is false, then $\hat{v}_{2} \in T_{2}$ exists such that $x\left(r, \hat{v}_{2}\right)>\hat{v p}\left(r, \hat{v}_{2}\right)$ and $p\left(v, \hat{v}_{2}\right) \neq 1$. Because $\mathrm{x}\left(\mathrm{r}, \hat{\mathrm{v}}_{2}\right)>\hat{\mathrm{v}} \mathrm{p}\left(\mathrm{r}, \hat{\mathrm{v}}_{2}\right)$, EXPIR and DET imply that $\mathrm{p}\left(\mathrm{r}, \hat{\mathrm{v}}_{2}\right)=1$. Thus, from MON(ii), $x\left(r, v_{2}\right)>\hat{v} p\left(r, v_{2}\right)$ for all $v_{2} \geq \hat{v}_{2}$. Because $p\left(v, \hat{v}_{2}\right) \neq 1, \operatorname{MON}(i)$ implies that $p\left(v, v_{2}\right) \neq 1$ for all $\mathrm{v}_{2} \leq \hat{\mathrm{v}}_{2}$. Hence, 


$$
\begin{aligned}
\hat{p}(r, \hat{v}) & =E\left[p\left(r, \tilde{v}_{2}\right) 1_{\left\{x\left(r, \tilde{v}_{2}\right)>\hat{v} p\left(r, \tilde{v}_{2}\right)\right\}}\right] \\
& =E\left[1_{\left\{x\left(r, \tilde{v}_{2}\right)>\hat{v p}\left(r, \tilde{v}_{2}\right)\right\}}\right] \\
& \geq E\left[1_{\left\{\tilde{v}_{2} \geq \hat{v}_{2}\right]}\right] \\
& \geq E\left[1_{\left\{p\left(v, \tilde{v}_{2}\right)=1\right\}}\right]=p_{1}(v),
\end{aligned}
$$

contrary to Lemma 2(ii). So (20) is true.

Inclusions (19) and (20) imply that

$$
1_{\left\{\mathrm{p}\left(\mathrm{v}, \tilde{\mathrm{v}}_{2}\right)=1\right\}}{ }^{1}\left\{\mathrm{p}\left(\mathrm{r}, \tilde{\mathrm{v}}_{2}\right)=1\right\}{ }^{1}\left\{\mathrm{x}\left(\mathrm{r}, \tilde{\mathrm{v}}_{2}\right)>\hat{\mathrm{v}}_{\left.\mathrm{v}\left(\mathrm{r}, \tilde{\mathrm{v}}_{2}\right)\right\}}=1_{\left\{\mathrm{x}\left(\mathrm{r}, \tilde{\mathrm{v}}_{2}\right)>\hat{\mathrm{v}}_{\mathrm{p}}\left(\mathrm{r}, \tilde{\mathrm{v}}_{2}\right)\right\}}\right.
$$

for all $\tilde{\mathrm{v}}_{2} \in \mathrm{T}_{2}$. Substituting (21) into (18) yields

$$
\begin{aligned}
& \left.\mathrm{U}_{1}(\mathrm{v}, \mathrm{v}) \geq \mathrm{E}\left[\mathrm{x}\left(\mathrm{r}, \tilde{\mathrm{v}}_{2}\right)-\mathrm{v}\right] 1_{\left\{\mathrm{x}\left(\mathrm{r}, \tilde{\mathrm{v}}_{2}\right)>\hat{\mathrm{v}} \mathrm{p}\left(\mathrm{r}, \tilde{\mathrm{v}}_{2}\right)\right\}}\right] \\
& =E\left[\left[x\left(r, \tilde{v}_{2}\right)-v p\left(r, \tilde{v}_{2}\right)\right] 1_{\left\{x\left(r, \tilde{v}_{2}\right)>\hat{v} p\left(r, \tilde{v}_{2}\right)\right\}}\right] \\
& =\hat{x}(r, \hat{v})-v \hat{p}(r, \hat{v}),
\end{aligned}
$$

where the first equality follows from DET and EXPIR (the latter because it implies that $\mathrm{x}=0$ if $\mathrm{p}=0$ ), and the second equality follows from the definition (14). Observe that (22) contradicts Lemma 2(i). Hence, $(p, x)$ must satisfy IC* Q.E.D. 


\section{References}

1. R. J. Aumann, M. Maschler and R.E. Stearns, "Repeated Games of Incomplete Information: An Approach to the Non-Zero-Sum Case," Report to the U.S. Arms Control and Disarmament Agency, Contract S.T. 143, prepared by Mathematica Inc., Princeton, 1968.

2. I. Barany, "Fair Distribution Protocols or How the Players Replace Fortune," CORE Discussion Paper No. 8718, 1987.

3. K. Chatterjee and W. Samuelson, Bargaining under incomplete information, $O p$. Res. 31 (1983), 835-851.

4. V. Crawford, and J. Sobel, Strategic information transmission, Econometrica $\mathbf{5 0}$ (1982), 1431-1452.

5. J. Farrell, "Credible Neologisms in Games of Communication," MIT Working Paper No. 386, 1985.

6. J. Farrell, and R. Gibbons, "Cheap Talk Can Matter in Bargaining," M.I.T. Working Paper No. 422, 1987.

7. F. Forges, An approach to communication equilibria, Econometrica 54 (1986), $1375-1386$.

8. F. Forges, "Equilibria with Communication in a Job Market Example," CORE Discussion Paper No 8703, 1987.

9. F. Forges, "Universal Mechanisms," CORE Discussion Paper No. 8704, 1987.

10. S. Grossman, and M. Perry, Perfect sequential equilibrium, J. of Econ. Theory 39 (1986), 97-119.

11. S. Hart, Non-zero-sum two-person repeated games with incomplete information, Math. of Op. Res. 10 (1985), 117-153.

12. O. Hart and B. Holmstrom, The theory of contracts, in "Advances in Economic Theory," ed. T. Bewley, Cambridge University Press, Cambridge, 1986. 
13. W. Leininger, P. Linhart, and R. Radner "The Sealed Bid Mechanism for Bargaining with Incomplete Information," AT\&T Bell Laboratories, mimeo, 1986.

14. S. Matthews, "Veto Threats: Rhetoric in a Bargaining Game," Pennsylvania, CARESS Working Paper No. 87-06, 1987.

15. S. Matthews, M. Okuno-Fujiwara, and A. Postlewaite, "Stability against Information Revelation," Pennsylvania, mimeo, 1988.

16. R. Myerson, Optimal coordination mechanisms in principal-agent problems, $J$. of Math. Econ. 10 (1982), 67-81.

17. R. Myerson, Analysis of two bargaining problems with incomplete information, in "Game-Theoretic Models of Bargaining," ed. A. Roth, Cambridge University Press, Cambridge, 1985.

18. R. Myerson, Bayesian equilibrium and incentive-compatibility: an introduction, in "Social Goals and Organization," ed. L. Hurwicz, D. Schmeidler, and H. Sonnenschein, Cambridge University Press, Cambridge, 1985.

19. R. Myerson and M. Satterthwaite, Efficient mechanisms for bilateral trading, $J$. of Econ. Theory 29 (1983), 265-281.

20. J. F. Nash, Non-cooperative games, Ann. of Math. 54 (1951), 286-295.

21. R. Radner and A. Schotter, "The Sealed Bid Mechanism: An Experimental Study," New York University, mimeo, 1987.

22. J. Riley and R. Zeckhauser, Optimal selling strategies: when to haggle, when to hold firm, Quart. J. of Econ. 98 (1983), 267-287.

23. M. Satterthwaite and S. Williams, "Bilateral Trade with the Sealed Bid Double Auction: Existence and Efficiency," Northwestern, CMSEMS Discussion Paper No. $723,1987$.

24. V. Smith, A. Williams, K. Bratton, and V. Vannoni, Competitive market institutions: double auctions vs. sealed bid-offer auctions, Amer. Econ. Rev. 72 (1982), 58-77.

25. S. Williams, Efficient performance in two agent bargaining, J. of Econ. Theory 41 (1987), 154-172. 
26. R. Wilson, Incentive efficiency of double auctions, Econometrica $\mathbf{5 3}$ (1985), 1101-1115.

27. R. Wilson, Efficient trading, in "Issues in Contemporary Microeconomics and Welfare," ed. G. Feiwel, Macmillan, New York, 1985.

28. R. Wilson, Game-theoretic analyses of trading processes, in "Advances in Economic Theory," ed. T. Bewley, Cambridge University Press, Cambridge, 1987. 